\title{
"Modicx fidei quare dubitastįi Una lectura del pontificado de Calixto III (1455-†1458) a partir de las imágenes monetales
}

\section{«Modica fidei quare dubitasti?» A reading of the pontificate of Calixtus III (1455-†1458) from images on coins}

Alberto AguilerA

albertoaguileraher@yahoo.es

Centro de Estudios Borjanos - Institución Fernando el Católico

Resumen: El presente artículo analiza el pontificado de Calixto III (1455-†1458) a partir de la función propagandística y la dimensión comunicacional de las imágenes y leyendas que figuran en la moneda pontificia, señalando tanto los puntos de continuidad con la amonedación de sus predecesores en el solio de San Pedro, como las novedades que se introdujeron en relación a la cruzada proyectada contra el Islam.

Palabras clave: Calixto III, Numismática, Medallística, cecas pontificias, propaganda.

Abstract: This article studies the pontificate of Calixtus III (1455-†1458) from the propaganda function and communicational dimension of the images and inscriptions appearing on papal coinage. Attention is paid to points of continuity with the monetary issues of his predecessors on the throne of St. Peter, as well as novelties introduced in relation to the planned crusade against Islam.

Keywords: Calixtus III, Numismatics, Medals, pontifical mints, propaganda 
Alberto Aguilera. «Modica fidei quare dubitasti?» Una lectura del pontificado de Calixto III (1455-†1458) a partir de las imágenes monetales

\section{Introducción}

El 18 de abril de 1455 Alonso de Borja (*1378-†1458) era elegido el Papa n. ${ }^{\circ} 209$ de la Iglesia católica a la edad de 77 años. Comenzaba un breve pontificado que se iba a caracterizar ante todo, pero no solo, por la organización de una cruzada contra el turco que terminó fracasando a pesar del ardor que puso el pontífice y que trabajos como los de M. Navarro (2002: 11-32; 2003; 2006) han valorado en su justa medida frente al posicionamiento de la historiografía tradicional, que vio en este intento de reconquista el eje exclusivo sobre el que giró la totalidad de las actuaciones y decisiones de sus años de gobierno, situado cronológicamente entre los de los papas humanistas Nicolás V (1447-†1455) y Pío II (1458-†1464), circunstancia esta que tampoco ha ayudado a valorar adecuadamente el perfil y la obra del primer papa Borgia. ${ }^{1}$

Nosotros hemos querido acercarnos a su figura desde una óptica una tanto inusual en los trabajos científicos de los que viene siendo objeto el pontificado calixtino, pues la inmensa mayoría prescinden de la moneda y de su enorme valor como documento histórico, primario y oficial (Mozas 2003: 153-156). A lo sumo, podemos encontrarnos referencias a las cantidades acuñadas en relación a la cruzada $^{2}$ o bien a sus medallas, pero siempre resaltando el valor artístico de estas últimas y pasando por alto, o incluso confundiendo, el momento en el que fueron acuñadas o fundidas cuando, a efectos de propaganda religiosa y política, que son los dos pilares en los que vamos a sustentar nuestro discurso, es un dato fundamental porque su impacto variará, al igual que las motivaciones e intenciones que llevaron a su fabricación, dependiendo de si se trata de una pieza contemporánea al hecho que conmemora o de si es una pieza de restitución. ${ }^{3}$ Como excepción contamos con el estudio de J. M. ${ }^{a}$ de Francisco Olmos (2010: 189-195), que proporciona una acertada síntesis general de los sellos, medallas y monedas más representativas batidas a nombre de Calixto III.

1 Las obras monográficas de S. Schüller (1991: 11-77) y Ó. Villarroel (2005: 17-72) ofrecen valoraciones generales del pontificado de Calixto III. Asimismo, también resultan de interés los corpora documentales aparecidos en los últimos años en la serie Diplomatari Borja (Batllori 2002; López 2004; 2005 y 2007) o el realizado por M. Navarro (2008).

2 Como ha puesto de manifiesto I. Ait (2007: 14-15), al poco tiempo de asumir el Papado Calixto III arrendó la Depositaría de la Cámara Apostólica a la sociedad Miraballi-Spannocchi, mientras dejaba en manos del sienés Ambrogio Spannocchi la denominada Depositeria della Crociata, encargada de gestionar la organización de la empresa militar proyectada por el Pontífice.

3 Tal caso podemos encontrarlo, por ejemplo, en M. Navarro (2002: 14, nota n. 으, que al argumentar que Calixto III tenía plena conciencia de haber sido elegido por Dios para llevar a cabo la cruzada afirma que: "Ut fidei hostes perderem elexit me", hizo grabar más tarde en el reverso de una medalla que conmemoraba los menudos éxitos de la flota que había enviado, bajo el mando del cardenal Trevisán, a las aguas del Egeo, dejando así constancia de su fe en la misión confiada por la divina Providencia a su pontificado». Sin embargo, la medalla a la que se refiere el autor no es contemporánea al hecho histórico, sino que se trata de una pieza de restitución (CNORP 50) realizada por Girolamo Paladino hacia 1664, dentro de una serie integrada por otras cuarenta y nueve medallas más que homenajean a los Pontífices que se sucedieron en la cátedra de San Pedro desde Martín V (1417-†1431) hasta Pablo III (1534-†1549), la cual fue auspiciada por el cardenal Francesco Barberini $(* 1597-\dagger 1679)$. Para profundizar en el estudio específico de esta serie remitimos a los trabajos de R. Martini (1987: 7-37) y A. Modesti (1988: 7-57), mientras que D. Velestino (2010: 124-133) aborda desde una perspectiva más general la popularidad alcanzada por las medallas de restitución a partir del siglo XVI. 
Alberto Aguilera. «Modica fidei quare dubitasti?» Una lectura del pontificado de Calixto III (1455-†1458) a partir de las imágenes monetales

Vaya por delante la advertencia de que la línea argumental de estas páginas se sostiene en la interpretación iconológica e iconográfica de las imágenes monetales y en el estudio de las leyendas a ellas vinculadas. ${ }^{4}$ En este sentido, no hemos renunciado a recurrir en alguna ocasión a las medallas, dado que su valor propagandístico está fuera de toda duda, pero debe tenerse en cuenta que, al carecer de una función económica propiamente dicha, la repercusión de su mensaje fue menor. En efecto, las diferencias entre la moneda y la medalla, particularmente por su misma naturaleza y funcionalidad, encuadran a esta última en unos circuitos mucho más reducidos y cerrados, ya no solo porque su fabricación no fuera derecho exclusivo del Estado, sea cual sea su forma de gobierno, y sí el de la acuñación de moneda como acto inequívoco de soberanía, sino porque al no tener un valor de cambio no circula ni viaja, no se mueve de mano y mano y, en consecuencia, tampoco los mensajes que sus imágenes y epígrafes trasladan al usuario (Travaini 2007: 83-87).

Esos mensajes propagados desde Roma, Foligno y Aviñón, las únicas cecas pontificias que se mantuvieron activas con Calixto III (1455-†1458), son los que pretendemos poner de relieve en estas páginas. Tras un primer epígrafe, en el que hemos considerado necesario aclarar algunas cuestiones metodológicas en relación a la moneda como documento histórico y a su valor como medio de propaganda política, agrupamos toda la producción que puede ser juzgada en una línea continuista con la de sus predecesores en el solio de San Pedro. De esta forma, al igual que la amonedación comunal italiana presenta un repertorio iconográfico iterativo y, con frecuencia, invariable en el tiempo como signo de garantía del poder emisor (Travaini 2007a: 484-485), la pontificia también suele ser repetitiva, potenciado aquellas composiciones más ligadas a la primacía petrina para justificar el doble poder espiritual y temporal que reside en los Papas. En estos casos, la continuidad en el marco que ofrece la tradición debe valorarse como garante de legitimación de un poder no hereditario por vínculos de sangre. ${ }^{5}$

Tampoco faltan ejemplos en los que la moneda se puso al servicio de la auto-representación del linaje de los Borgia, redundando en el prestigio familiar al ligarse a la Sede de San Pedro como una nueva dinastía papal, aunque tal comportamiento no puede ser considerado como

4 El principal catálogo de referencia para la moneda medieval y moderna italiana sigue siendo el CNI, para cuya contextualización histórica en el periodo en el que fue elaborado, su impacto y la enorme importancia en la historiografía numismática italiana dirigimos al monográfico que le fue dedicado por A. Savio y A. Cavagna (2010). No obstante, a lo largo de estas páginas hemos optado por manejar indistintamente los corpora de F. Muntoni (1972) y A. G. Berman (1991), más especializados en la moneda pontificia. También destaca la clasificación que realizó G. Berni (1948) de todas las monedas a nombre de los pontífices españoles.

5 La impronta en el monetario calixtino de las reformas y del dirigismo del que hicieron gala Martín V (1417-†1431) y Eugenio IV (1431-†1447), como parte de un programa de actuaciones mucho más amplio y complejo encaminado a la restauración y fortalecimiento del dominio temporal y espiritual del Papado, resulta muy importante desde el punto de vista iconográfico. A este respecto, I. Ait (2011: 157-172) llega a interesantes conclusiones sobre el intervencionismo pontificio en la ceca de Roma, en particular sobre las decisiones que afectaron al peso y al valor de los ducados papales y ducados romanos, mientras que P. Prodi (1982) ha puesto en conexión la derrota del Conciliarismo con la afirmación ideológica de una nueva monarquía papal y con el proceso de transformación del Papado medieval en un naciente y nuevo estado moderno, que tuvo importantes manifestaciones visibles en la iconografía y epigrafía monetal. 
Alberto Aguilera. «Modica fidei quare dubitasti?» Una lectura del pontificado de Calixto III (1455-†1458) a partir de las imágenes monetales

una innovación de Calixto III según se analiza en el tercer apartado. Finalmente, en el último de los epígrafes se valoran todas las novedades iconográficas y epigráficas que se produjeron en esta amonedación, siempre en relación directa con la movilización del orbe católico contra la amenaza otomana. Sin embargo, estos emblemas y rótulos no se limitaron a actuar como un recurso propagandístico puntual, sino que redefinidos a contextos históricos distintos a los que motivaron su creación, también tuvieron una importante proyección posterior suponiendo, sin lugar a dudas, la herencia más importante de Calixto III a la moneda pontificia.

\section{Cuestiones metodológicas previas}

Un hecho casi unánimemente admitido por la historiografía es que la moneda reviste de una función propagandística y de una dimensión comunicacional, aunque no existe tanto consenso a la hora de evaluar el grado de efectividad real y la magnitud de su impacto. ${ }^{6}$ En lo fundamental, las discusiones se han centrado con mayor intensidad en la moneda romana, aunque los argumentos en pro y en contra pueden hacerse extensivos a la acuñada más tarde. De esta forma, la relevancia que se le había conferido tradicionalmente como potente medio de difusión de determinados valores ideológicos y a su eficacia comunicativa a través de imágenes y rótulos fue cuestionada, entre otros, por R. Jones (1956: 13-33) y M. Crawford (1983: 62), para quienes resultó bastante limitada en contraposición a las posturas de C. H. V. Sutherland (1983: 73-82), que posiblemente gozan de mayor aceptación en la actualidad y que nosotros mismos asumimos en nuestra tesis doctoral (Aguilera 2015: 19-30).

Con todo, y situándonos en los planteamientos teórico-metodológicos propuestos por la semiología y la sociología del arte, la moneda contiene signos ligados a un significante, a unas circunstancias concretas y a uno o más significados que deben ser descodificados a partir de su propio ámbito cultural. Se conforma de esta manera un proceso comunicativo intencionado cuyos agentes protagonistas se identifican con un emisor -único o múltiple - y con un receptor -individual o colectivo- unidos por un código, un canal y un contexto que conducen a la producción del mensaje que, insistimos, debe descifrarse dentro del marco en el que se ha emitido y para el cual se ha puesto en circulación, a partir de los propósitos del emisor ${ }^{7}$ y, por supuesto, teniendo en cuenta la significación polisémica que puede tener un mismo icono si se operaron cambios en la realidad política, religiosa y socioeconómica que lo generó en un principio. ${ }^{8}$

6 L. Travaini (2009: 13-61) analiza con detalle esta misma problemática.

7 Esta intencionalidad es la que determina la diferencia entre los términos «publicidad»y «propaganda», que tan a menudo actúan como sinónimos en nuestro lenguaje actual (Castillo 2009: 14) aunque solo la contenga el segundo.

8 En lo fundamental, seguimos los argumentos de R. Jakobson y M. Halle (1967) sobre la base del Organon-Model fijado por K. Bühler (1934/2011). El funcionamiento del proceso es descrito con acierto por Castillo (2009: 13-14) 
Se trata, en definitiva, de superar los análisis formalistas y funcionalistas como de manera insistente han demandado autores como P. Zanker (1989), aunque para otros, como F. Salcedo (1999: 87109), el estilo también pueda contribuir a clarificar el mensaje a partir del análisis de la forma. Superadas pues las corrientes positivistas, en parte gracias a la escuela materialista italiana, en el día de hoy domina una postura que defiende entender a una determinada obra como portadora y transmisora de ideas, conceptos y, en nuestro caso, también de mensajes propagandísticos en sus contextos histórico, religioso y cultural, que son los que queremos subrayar en estas páginas en relación con las monedas acuñadas por Calixto III (1455-†1458).

\section{La amonedación calixtina en el marco de la tradición}

El 5 de julio de 1455, menos de dos meses después de que Alfonso de Borja se convirtiera en Calixto III, el florentino Francesco Mariani Francisci, que comenzó a trabajar en la ceca de Roma veinte años antes (Ait 2011: 167), renovó su contrato de arrendamiento y asumió la acuñación de ducados papales o florines (fig. 1), grossi y piccioli siguiendo las indicaciones contenidas en una capitulación que también reguló los tipos monetales y las leyendas que tenían que aparecer en cada uno de los nominales (Martinori 1918a: 34-35). El anverso de los ducados (Muntoni 3-4; Berman 348) alberga el escudo del Papa junto a la leyenda CALISTVS PAPA III, mientras que en el reverso se muestra a San Pedro en posición estante y hacia el frente, con las llaves en su mano derecha y un libro en la izquierda circundado por el rótulo S PETRVS ALMA ROMA (Martinori 1918a: 30). Los grossi (Muntoni 10-13; Berman 351) participan del mismo tipo y epígrafe en su cara principal, pero para el reverso se prefirió el diseño de los santos apóstoles Pedro y Pablo, estantes y de frente, con sus respectivos atributos iconográficos y el epígrafe S PETRVS S PAVLVS ALMA ROMA (Martinori 1918a: 30-31) completando la escena. No obstante, hay que tener en cuenta que Francesco Mariani también batió ducados (Muntoni 5; Berman 349) bajo una iconografía y epigrafía ${ }^{9}$ similar a la asignada a los grossi, aunque su fabricación no aparezca referida en la contrata.

en los casos de la arquitectura, el urbanismo y las producciones artísticas mayores y menores. Más centrados en el ámbito numismático son los planteamientos expuestos en algunos de los trabajos de Chaves (2009: 317-359; 2012: 173-206) dedicados al estudio de la moneda como marcadora de identidades y de procesos evolutivos en la etnogénesis de las comunidades cívicas en la Antigüedad. La autora distingue correctamente entre el nivel emisor de las monedas y el receptor, interrogándose sobre si los marcadores culturales de ambos fueron o no coincidentes, y valorando a la moneda como un documento multifuncional dentro de los tres parámetros que estimulan su acuñación y en los que se mantuvo durante su circulación: el «psicológico-propagandístico», el «político»y el «financiero-económico». Este esquema teórico sobre la iconografía monetaria como fenómeno identitario es completamente válido para otras épocas históricas, resultando de interés el trabajo de J. M. de Francisco Olmos (2012: 59-96) para la moneda medieval.

9 Como única diferencia significativa cabe mencionar la reformulación de la leyenda S PETRVS S PAVLVS ALMA ROMA, que tenemos en el reverso de los grossi, por la mención S PETRVS S PAVLVS y el topónimo ROMA en el exergo que aparece en los ducados. De cualquier forma, la autoría de Mariani queda confirmada por la rosa de cinco pétalos que figura en ellos como marca personal. 


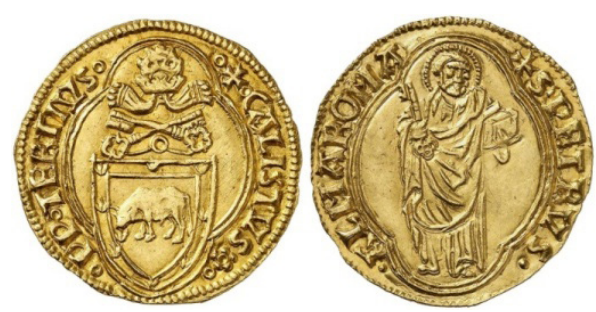

Figura 1. Ducado papal de Calixto III (Muntoni: 3; Berman 348), acuñado en Roma con su escudo de armas y San Pedro. Fritz Rudolf Künker GmbH \& Co. KG. Auction 283, lot. 5692, 29-30 September 2016. (Foto: sixbid.com).

Adentrándonos más en profundidad en el estudio de los tipos monetales, lo primero que tenemos que destacar es que no puede afirmarse que la presencia del escudo personal del Papa en la cara principal del oro y la plata fuera algo nuevo en la amonedación pontificia romana. Al contrario, sigue la línea que Martín V (1417-†1431) inició en la Ciudad Eterna y que continuaron Eugenio IV (1431-†1447) y, en cierta forma, también Nicolás V (1447-†1455), pues aunque renunció a tener un escudo personal ${ }^{10}$ asumió el de la Sede Apostólica como propio (Berman 1993: 13). ${ }^{11}$ En cualquier caso, opinamos que la asunción de los escudos como tipo principal tiene que entenderse en el contexto de ese importante momento transicional iniciado en el último cuarto del siglo XIV, cuando en Roma se asistió al traspaso progresivo de la prerrogativa de acuñación desde las autoridad ciudadana a la pontificia, hecho interpretado por I. Ait (2011: 164-165) no solo como la manifestación de una clara voluntad de la nueva política papal, encaminada a la centralización en ella de todos los instrumentos de gobierno y de los cuales la moneda era un componente fundamental, sino como el deseo expreso de difundir la suprema autoridad del Papa frente a una Iglesia debilitada por el Cisma de Occidente y fuertemente dividida por el Conciliarismo.

Por otra parte, la representación de San Pedro fue una constante en la moneda pontificia a partir de los denarios (Muntoni 3; Berman 13) de San León III (795-†816), pero estas composiciones iniciales siempre se limitaron a su busto o media figura ${ }^{12}$ hasta que la celebración del Jubileo de 1300 marcó una nueva e interesante conceptualización icónica que quedó reservada a los grossi

10 Para P. Prodi (1982: 98) esta renuncia supone una manifestación pública de la transformación del poder directo y real del Papado que se estaba experimentado desde las primeras décadas del siglo XIV, diverso al modelo medieval propuesto por Bonifacio VIII (1294-†1303).

11 Aunque la costumbre de acuñar con los escudos personales de los Papas dio comienzo en Aviñón, en la Urbs pueden localizarse interesantes antecedentes en las emisiones a cargo del Senado Romano, en las que destacados linajes, siguiendo la tradición inaugurada por Carlos de Anjou (*1227-†1285) a mediados del siglo XIII, grabaron sus emblemas familiares como forma de ostentación aristocrática (Bultrini 2013: 221-238).

12 En torno a esta tipología monetal y a otras de las que fue objeto San Pedro en las cecas italianas remitimos a la obra de V. G. Moneta (2010: 87-103). 
Alberto Aguilera. «Modica fidei quare dubitasti?» Una lectura del pontificado de Calixto III (1455-†1458) a partir de las imágenes monetales

samperini (Berman 114-116), acuñados entonces a nombre del Senado Romano. Por primera vez se concibió estante, con las llaves pendientes de su mano derecha y con un libro en la izquierda aunque, si bien es cierto, relegado a la cara secundaria en favor de San Pablo, que es quien preside la moneda en idéntica pose, con libro y espada como atributos y la leyenda ROMANI PRICIPE. ${ }^{13}$ Nos encontramos, por lo tanto, ante unas nuevas composiciones que pudieron tomar como modelo las dos estatuas que Bonifacio VIII (1294-†1303) hizo colocar en la logia de las bendiciones de San Juan de Letrán (Travaini 2001: 123), dado que estos samperini también fueron las primeras monedas en mostrar una representación iconográfica monetal en Roma del Apóstol de los Gentiles, ${ }^{14}$ aunque no en contener una mención epigráfica que tenemos ya sobre los denarios (Muntoni 4; Berman 43) de Esteban VI (V) (885-†891) batidos entre el 888 y el 891.

A pesar de estos antecedentes, la figuración conjunta de ambos apóstoles en una misma cara de la moneda, tal y como se muestran con Calixto III (fig. 2), no fue adoptada hasta la emisión de grossi de Eugenio IV (1431-†1447), quedando perpetuada sobre estos mismos valores y en los ducados papales de Nicolás V (1447-†1455). Esta continuidad con la línea iconográfica marcada por el papa Condulmer puede hacerse extensiva de igual modo al ámbito epigráfico, pues al margen de los rótulos del anverso, que evidentemente recogen la identidad de cada uno de los Pontífices, los del reverso son herederos de la política monetaria de Eugenio IV, a quien se debe la progresiva sustitución del letrero ROMA CAPVT MVNDI como lema característico de la amonedación que había estado a cargo del Senado, por el de ALMA ROMA, que es el que define en esos momentos a la pontificia con diferentes combinaciones y variantes (Martinori 1918: 32-36). ${ }^{15}$

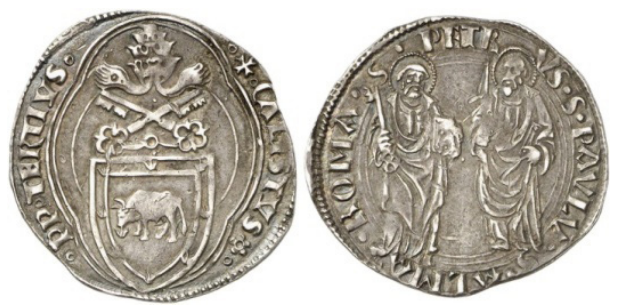

Figura 2. Grosso de Calixto III (Muntoni 10; Berman 351), acuñado en Roma con su escudo de armas y San Pedro y San Pablo. Fritz Rudolf Künker GmbH \& Co. KG. Auction 281, lot. 1671, 27-28 September 2016. (Foto: sixbid.com).

13 Hay que esperar al pontificado de Pablo III (1534-†1549) para que la imagen estante de San Pablo vuelva a presidir en solitario una moneda pontificia (Moneta 2010: 103).

14 Sobre las tipologías de las que fue objeto San Pablo en las cecas italianas puede consultarse la obra de V. G. Moneta (2010: 103-110).

15 Los ducados (Muntoni 3-4; Berman 348) con la imagen de San Pedro se acuñaron con la leyenda S PETRVS ALMA ROMA, mientras que los que incluyen a San Pablo (Muntoni 5; Berman 349) muestran el rótulo S PETRVS S PAVLVS con la mención ROMA en el exergo. En cambio, para los grossi (Muntoni 10-13; Berman 351) se decidió una combinación de las anteriores con la fórmula S PETRVS S PAVLVS ALMA ROMA. 
Alberto Aguilera. «Modica fidei quare dubitasti?» Una lectura del pontificado de Calixto III (1455-†1458) a partir de las imágenes monetales

Dejando aparcada por el momento la producción romana para centrarnos en la de Foligno, lo primero sobre lo que debe incidirse es que tampoco se comprueban puntos de ruptura en la epigrafía e iconografía de la ceca con respecto a Eugenio IV (1431-†1447) y Nicolás V (1447†1455), aunque quizá muestre una mayor dependencia con la del papa Parentucelli. Así es, la renovación del privilegio para que la ciudad pudiera volver a batir moneda fue una decisión de Eugenio IV, y a su nombre se pusieron en circulación piccioli (Muntoni 40-41; Berman 318) con la leyenda EVGENIVS PP QVA en el anverso cercando a los caracteres R T V S, que actúan como tipo principal dispuestos en forma cruciforme en el interior de un círculo. En contrapartida, para el reverso se escogió una cruz flordelisada ${ }^{16}$ como emblema cívico por antonomasia vinculado al rótulo VRBS FVLGINEI.

El taller mantuvo su producción con Nicolás V (1447-†1455), bajo cuyo pontificado acontecieron pequeñas novedades iconográficas en la moneda fraccionaria. Los piccioli (Muntoni 35; Berman 337) pasaron a estar presididos por las llaves en sotuer, ${ }^{17}$ pero se conservó la cruz flordelisada como tipo de reverso y, en lo fundamental, también la referencia toponímica, que ahora se reformuló como DE FVLGINEO. Igualmente se batieron quattrini (Muntoni 34; Berman 336) en los que el emblema cívico de la flor de lis se destinó al anverso para dar cabida en el reverso al obispo San Feliciano, patrón tutelar de la ciudad, junto a la leyenda S F D FVLGINEO. ${ }^{18}$ Con Calixto III la producción se limitó a piccioli (Muntoni 23; Berman 353) con los mismos tipos y leyendas que los documentados con Nicolás V (1447-†1455) sobre estos mismos valores (fig. 3).
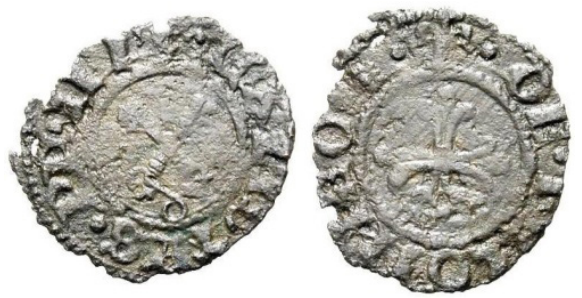

Figura 3. Picciolo de Calixto III (Muntoni 23; Berman 353), acuñado en Foligno con llaves en sotuer y cruz flordelisada.

Numismatica Ranieri S.r.l. Auction 8, lot. 429, 9 November 2015. (Foto: https://www.numisbids.com).

16 L. Travaini (2007c: 7-40) analiza la cruz como tipo en la moneda italiana hasta finales de la Edad Media.

17 Aunque las llaves aparecen conectadas a San Pedro desde al menos el siglo V, no se relacionaron con el Papado hasta el siglo XIII, ni tampoco directamente con la persona del Papa hasta Bonifacio VIII (1294-†1303), cuando recurrió a ellas como forma de legitimación personal (Travaini 2007b: 202-204). En cambio, como elemento individualizado figuraron por primera vez dispuestas en recto en los grossi paparini y denari paparini (Muntoni 1-2) acuñados en Viterbo durante la Sede Vacante de la que fue camarlengo Pietro di Montebruno (1268-1271), y colocadas en sotuer en el monetario (Muntoni 1-2) de la ceca de Pont de Sorgues a nombre de Clemente V (1305-†1314). En ambos casos, su adopción es entendida por A. Rovelli (2009: 187-189) como una clara reafirmación de la autoridad pontificia, aunque no en Roma, donde las circunstancias no lo hacían posible todavía.

18 Las representaciones iconográficas monetales de San Feliciano son analizadas en el estudio de de G. V. Moneta (2010: 139). 
La tercera de las cecas activas con Calixto III fue la de Aviñón, que acuñó oro, plata y vellón con los nominales de florín (Muntoni 16-17; Berman 354-355); carlino (Muntoni 19; Berman 356); ${ }^{19}$ blanca (Muntoni 18; Berman 357); ${ }^{20}$ douzain (Muntoni 20; Berman 358) y medio groso (Muntoni 21-22; Berman 359). A excepción de los primeros y los últimos, el resto se mantuvo dentro de la tradición iconográfica aviñonense desde que el papa Clemente VI (1342-†1352) batiera grossi (Muntoni 1; Berman 182). ${ }^{21}$ Por norma general, el elenco iconográfico se constituyó en una reducida variedad de motivos iconográficos (Francisco 2010: 193) que, a nuestro modo de ver, suelen aparecer jerarquizados dentro de las emisiones, determinando su importancia la cara y el valor que los contienen. No podemos entrar a valorar en detalle este comportamiento, pero no deja de ser llamativo que, salvo contadas excepciones, las composiciones de San Pedro o la del Papa entronizado $^{22}$ se reservaran para el oro y la plata emparejadas con la tiara y las llaves, mientras que en los valores fraccionarios se optara mejor por la mitra. ${ }^{23}$

Así lo vemos en el monetario calixtino, donde la escena del Pontífice en cátedra preside los carlinos a la par que una cruz pasante con pequeñas llaves en sotuer en el interior de todos los cuarteles resulta el icono característico del reverso con la leyenda SANTVS PETRVS. Este mismo espacio en los valores de blanca y douzain es el que acoge una insignia crucífera similar, aunque en el primer caso las llaves se sustituyeron por el triregno en los cuarteles 2 y 3 , mientras que en el segundo solo los cuarteles 1 y 4 son los que cobijan las llaves. En lo que afecta al anverso, los temas elegidos fueron el escudo personal de Calixto III y el tipo epigráfico P P / P P respectivamente, en ambos casos circundados por el letrero CALIXTVS PP TERTIVS.

\section{Propaganda familiar en la moneda pontificia}

El contrato suscrito con Francesco Mariani Francisci para el arrendamiento de la ceca de Roma también contempló la emisión de piccioli «similes illis, qui hodie currunt in Urbe» en los que debían grabarse el escudo de armas del Pontífice en el anverso y una cruz en el reverso (Martinori 1918a:

19 F. Muntoni no da como segura la identificación de la moneda con un carlino.

$20 \mathrm{El}$ autor considera probable dicha identificación.

21 A. G. Berman asigna a Aviñón la emisión de estos grossi clementinos, mientras que F. Muntoni la coloca bajo interrogante.

22 El tipo monetal que presenta al Papa entronizado apareció por primera vez en el pontificado de Juan XXII (1316†1334), tanto en los grossi (Muntoni 1) de la ceca de Macerata como en los de Pont de Sorgues (Muntoni 7).

23 Fue durante el pontificado de Inocencio III (1198-†1216) cuando se sentaron las bases que diferenciaban la tiara, como símbolo de poder del Papa, y la mitra, circunscrita a su magisterio sacerdotal. Sin embargo, y dado que la autoridad pontificia fue tanto espiritual como temporal, la tiara terminó por convertirse en la referencia por antonomasia de la plena potestad del Papado, alcanzando esta relación su punto de madurez con Bonifacio VIII (1294-†1303), posible ideólogo del triregno y primero que se hizo coronar en San Pedro antes de tomar posesión en San Juan de Letrán. Para profundizar en todos estos aspectos son referencia obligada los trabajos de A. Paravicini (1994; 1998 y 2009). 
Alberto Aguilera. «Modica fidei quare dubitasti?» Una lectura del pontificado de Calixto III (1455-†1458) a partir de las imágenes monetales

34), aunque lo que terminó figurando en solitario sobre la cara principal fue el buey de los Borja junto a la leyenda CALISTVS PP TERTIVS (Muntoni 14-15; Berman 352). El emblema supone un punto de ruptura con la política monetaria de su inmediato predecesor, que acuñó con la imagen del Santo Sudario sobre estos mismos valores, ${ }^{24}$ y no es menos esclarecedor el que la leyenda inscrita en el reverso fuera la divisa profana ROMA CAPVT MVNDI frente a la de ALMA ROMA que, recordemos, es la que se localiza sobre los ducados y grossi en correspondencia con la temática más religiosa de su iconografía, dirigida hacia la legitimación y reafirmación del poder del Papado a través de la representación visual del valor de la sucesión apostólica. Por estas razones, creemos que fue en esta moneda (fig. 4) de escaso valor, pero de uso corriente, donde en Roma se potenció una política propagandística de auto-representación familiar de los Borgia como nueva dinastía papal, mensaje que también se expuso con claridad en los mezzi grossi (Muntoni 21-22; Berman 359) de Aviñón, donde el toro timbrado por la mitra y flanqueado por los caracteres P P ocupa el anverso, o en los florines de esta misma ceca, (Muntoni 16-17; Berman 354-355), en los que se asocia a la tiara y las llaves en distintas combinaciones, aunque en ninguno de los casos fuera objeto de un tratamiento heráldico propiamente dicho (fig. 5).

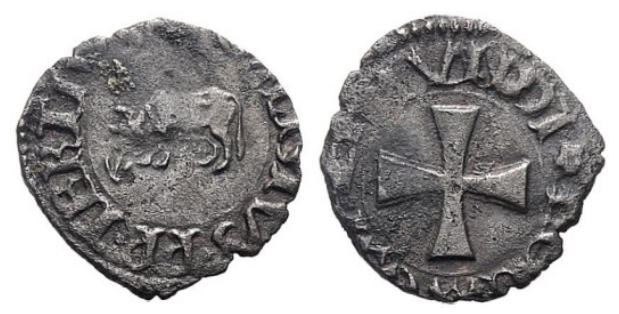

Figura 4. Picciolo de Calixto III (Muntoni 14-15; Berman 352) acuñado en Roma con el toro o buey.

Numismatica Ranieri S.r.l. Auction 5, lot. 394, 21 April 2013. (Foto: https://www.numisbids.com).

Así pues, el que una misma temática aparezca en dos cecas pontificias sobre valores tan desiguales obliga a plantearse la influencia que los circuitos de circulación monetaria de una y otra ejercieron en la elección de los programas iconográficos, pues la distinta identidad de aquellos que se consideraron como los receptores directos pudo ser la que determinó la adopción y el descarte de determinados tipos y leyendas. Sea como fuere, aunque esta exaltación en la moneda del linaje propio puede guardar ciertas conexiones con la práctica del nepotismo que la leyenda negra se ha encargado de magnificar, ${ }^{25}$ en ningún caso fue un comportamiento privativo de Calixto III. Los precedentes en la moneda resultan abundantes, y podemos traer a colación numerosos ejemplos sin ánimo de ser exhaustivos. El aragonés Benedicto XIII (1394-†1423) acuñó en Aviñón dobles dineros y dineros de vellón (Berman 248-249) con el creciente como tipo parlante de la poderosa

24 V. G. Moneta (2010: 43-44) trabaja las representaciones del Santo Sudario en la moneda.

25 Aunque Calixto III practicó el nepotismo, sus sobrinos no llegaron a desempeñar puestos políticos de excesiva relevancia a excepción de Rodrigo Borgia (Villaroel 2005: 62-63). 
Alberto Aguilera. «Modica fidei quare dubitasti?» Una lectura del pontificado de Calixto III (1455-†1458) a partir de las imágenes monetales

casa de los Luna; Inocencio VII (1404-†1406) tampoco renunció a batir en Roma grossi y mezzi grossi (Muntoni 1-5; Berman 250-252) con una estrella ${ }^{26}$ sobre las llaves cruzadas; el antipapa Juan XXIII (1410-†1419), de la familia Cossa, emitió grossi (Berman 256), carlinos y dobles dineros de vellón (Berman 261, 263) con el icono familiar de la pierna y, por último, Martín V (1417-†1431), Oddone Colonna antes de alcanzar el trono de San Pedro, también utilizó sobre determinados valores una columna coronada como insignia parlante de su estirpe.

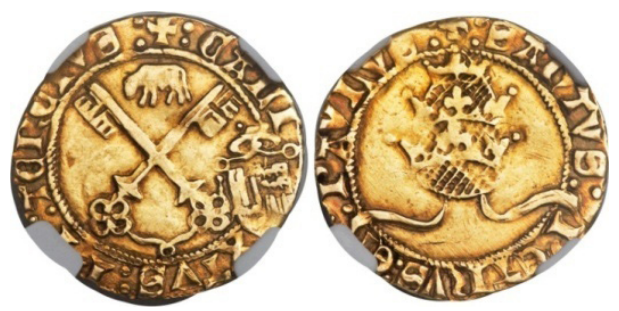

Figura 5. Florín de Calixto III (Muntoni 17; Berman 355) con el emblema familiar del toro en el anverso. Heritage World Coin Auctions. CICF Signature Sale 3046, lot. 30261. 14-15 April 2016. (Foto: https:/ /www.numisbids.com/)

Con todo, en la mayor parte de las ocasiones estos simbolos no recibieron un tratamiento como tipos principales ${ }^{27} \mathrm{ni}$ tampoco fueron «heraldizados» de forma aislada aunque simultáneamente sí se incluyeran en la representación de las armas de estos Papas y antipapas. ${ }^{28}$ Solo Eugenio IV (1431-†1447) incorporó su blasón familiar de la banda sin timbrar en algunas monedas con un valor complementario al de las imágenes principales, optando en otros momentos por el escudo propiamente dicho, timbrado con la tiara o con la tiara y las llaves (Bascapé / Del Piazzo / Borgia 1983: 329-330). Por ello, el que los piccioli romanos de Calixto III solo contengan el buey como tipo del anverso, sin estar emparejado a elementos iconográficos que pudieran favorecer una cierta «Sacralización» del icono, todo lo más a la cruz del reverso, expresa una carga ideológica distinta a cuando se suma al escudo de armas o se vincula a la tiara, llaves y mitra como vemos en Aviñón. En estos casos, acontece una exaltación de la figura personal de Calixto III como pontífice que redunda en el prestigio familiar y en el fortalecimiento de la imagen pública del Papado que él representa, frente a este segundo bloque de monedas con la composición solitaria del buey, más dirigidas hacia una glorificación de Alonso de Borja y de la familia y estirpe a la que pertenece. ${ }^{29}$

26 Lo que figura en el escudo de armas de este pontífice es un cometa.

27 Entre otros ejemplos destacan los piccioli (Muntoni 28-29; Berman 277) acuñados en Ascoli por Martín V (1417†1431), donde la columna coronada actúa como tipo principal en ambas caras.

28 El comportamiento parece que fue similar al demostrado en los sellos, en cuyo campo los papas de Aviñón hicieron colocar elementos vinculados a sus armas familiares. (Francisco 2010: 191, nota n ${ }^{\circ}$ 14).

29 La rica simbología del toro como emblema borgiano por antonomasia ha sido muy estudiada (Montesano 2001: 759-780; Company/Garín 2006: 229-394) para el pontificado de Alejandro VI (1492-†1503), pero no para el de Calixto 
Alberto Aguilera. «Modica fidei quare dubitasti?» Una lectura del pontificado de Calixto III (1455-†1458) a partir de las imágenes monetales

\section{La cruzada en la moneda de Calixto III}

En clara conexión con la planificación de la cruzada debe analizarse una parte importante del oro y la plata acuñada en Roma y que suponen un punto de inflexión con la iconografía y epigrafía de la amonedación pontificia previa (Francisco 2010: 194). Los valores batidos a los que nos referimos son ducados papales (Muntoni 1-2; Berman 347) y grossi (Muntoni 6-9; Berman 350), y en ambos casos las armas del Pontífice se ubican en el anverso, timbradas por la tiara y las llaves en sotuer junto al epígrafe CALISTVS PP TERTIVS. Las novedades, por lo tanto, se concibieron para el reverso con la representación sedente de San Pedro, remando en el interior de una barca mientras sujeta con la mano izquierda una gran cruz a modo de palo mayor, todo ello complementado por la divisa MODICE FIDEI QVARE DVBITATIS (fig. 6) que remite al episodio de Cristo caminando sobre las aguas del lago de Tiberíades recogido por el evangelista San Mateo (14, 28-31).

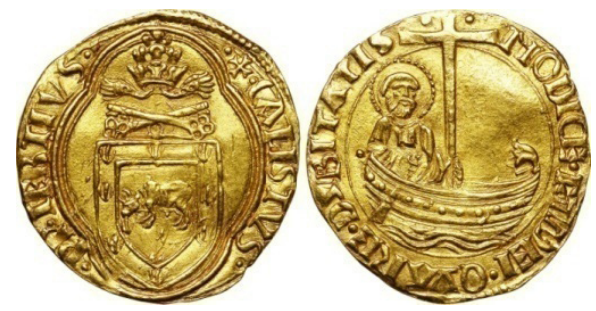

Figura 6. Ducado de Calixto III (Muntoni 1-2; Berman 347). Heritage World Coin Auctions. Signature Sale 3029, lot. 30169. 14-16 January 2014. Foto: https:/ / www.numisbids.com/).

Si no estamos equivocados, el tipo de la nave resultaba inédito en la moneda pontificia pero no en la medallística, ya que en 1455 Andrea Guazzalotti da Prato (c. 1435-†1495) (0) $^{30}$ ideó para el reverso de la medalla póstuma (CNORP 22) de Nicolás V (1447-†1455) una escena similar que presentaba la imagen del propio Pontífice con tiara y revestido con capa pluvial, sentado al timón de una barca cuyo borde contiene la leyenda ECLESIA mientras sujeta una cruz con la bandera de la Santa Sede. ${ }^{31}$ Esta composición de la navis Ecclesiae o navicula Petri, aunque de larga tradición

III. Sobre este último, S. Maddalo (2006: 413-414) ha señalado que recurrió a su ostentación en las obras por él auspiciadas de forma muy moderada, pues fue a partir de Sixto IV (1471-†1484) cuando se comenzó a hacer un uso mucho más propagandístico de este tipo de imágenes, aunque todavía no de forma articulada. Según esta misma autora, tras la elección de Alejandro VI el bóvido asumió numerosos significados simbólicos hasta desempeñar un rol central en los discursos narrativos y figurativos promovidos por el Papa en sus empresas artísticas más importantes, caso de los ciclos pictóricos de los Apartamentos Borgia del Vaticano pero, a nuestro entender, el animal ya pudo tener estas cargas semánticas con Calixto III, al menos una parte de ellas. En relación a este tema, queremos recordar que no puede seguir sosteniéndose que los Borja tomaran el toro del escudo de armas de la ciudad aragonesa de Borja (Zaragoza), tal y como hemos analizado recientemente (Aguilera: 2016: 1-20).

30 El clásico de J. Friedlaender (1862) y las más ecientes aportaciones de L. Simonato (2003: 513-516) analizan el perfil biográfico, humano y profesional del personaje.

31 Esta medalla supone un cambio estilístico muy importante con respecto a la primera papal conocida, acuñada 
Alberto Aguilera. «Modica fidei quare dubitasti?» Una lectura del pontificado de Calixto III (1455-†1458) a partir de las imágenes monetales

cristiana, se desarrolló con fuerza en la Baja Edad Media y se consolidó en la época de la Reforma y Contrarreforma, Sin embargo, como señaló J. L. Calbarro (2002: 297-309), en ocasiones puede encerrar un significado más individualista que resalta que solo formando parte de ella es posible alcanzar el puerto celestial y gozar de la salvación eterna. Este, sin embargo, no fue el mensaje último que pretendieron transmitir las monedas que nos ocupan.

En efecto, el sentido se vio modificado al hilo de las circunstancias históricas que generaron su elección como tipo monetal, primando el concepto de lucha contra el infiel en aras del triunfo de la Iglesia. La nave quedó en cierta forma «militarizada», no tanto por el tratamiento formal de la imagen en sí, sino por un contexto sobradamente conocido por unos usuarios que vieron en ella el liderazgo de Calixto III y, además, con interesantes matices que enriquecen y concretan el mensaje. Porque no es el Papa quien pilota la barca como vemos en la medalla de Nicolás V (fig. 7), sino que la dirección queda delegada en San Pedro, que navega seguro y en la orientación correcta con el apoyo de Cristo. La legitimidad de la empresa se confirma y propaga de esta forma como un proyecto querido por Dios, dispuesto a actuar como valedor y garante de la victoria a pesar de la desconfianza humana.

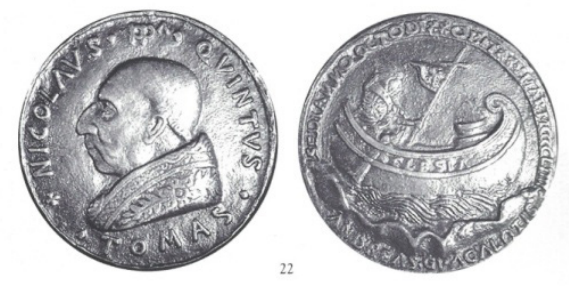

Figura 7. Medalla póstuma de Nicolás V (1447-1455) realizada por Andrea Guazzalotti da Prato en 1455 con la escena de la Navicula Petri. (Foto: CNORP 22).

Dichas valoraciones han apoyado la idea de que estas monedas fueron las primeras pontificias en contener un preciso e intencionado mensaje (Martinori 1918a: 27-28), así como su relación directa con la flota papal que zarpó del puerto de Ostia en mayo de 1456 (V. G. Moneta 2010: 96), o su interpretación como una enérgica reprimenda del Papa a los monarcas europeos por haberlo abandonado a su suerte (Martinori 1918a: 27-28). La primera de las afirmaciones no la compartimos porque las imágenes y leyendas previas no fueron elegidas nunca al azar y, con respecto a la segunda, tampoco podemos asumirla en su totalidad puesto que, aunque su vinculación con

en 1439 para celebrar la unión de las Iglesias griega y armenia (CNORP 11) durante el pontificado de Eugenio IV (1431-†1447), y que fue la primera en fabricarse de forma contemporánea al hecho que conmemora dado que las documentadas de Martín V (1417-†1431) son todas de restitución (CNORP 1-10). Su fuerte dependencia iconográfica con las monedas medievales le imprimen una conceptualización muy lejana a la característica medalla renacentista, de la que ya hacen gala los ejemplares de Guazzalotti, lo que corrobora que el artista era conocedor de los trabajos de Antonio di Puccio Pisano (c. 1395 - †c. 1455) o los de Matteo de' Pasti (†ant. 1467). 
la flota es innegable, no creemos que su emisión tuviera lugar al comienzo o en los momentos previos de la intervención militar tal y como se sugiere. Al contrario, la conceptualización estilística de la escena y la leyenda a ella emparejada son argumentos lo suficientemente sólidos como para retrasar su fabricación hasta después de la victoria de Belgrado y antes de que una segunda flota se dirigiera a Rodas y Chipre en 1457, ya que, en nuestra opinión, solo contando con una victoria como aval el mensaje encuentra mejor acomodo cronológico. La misma leyenda latina contenida en las monedas: «Hombre de poca fe ¿por qué has dudado?» nos sitúa en el texto evangélico mateano en el momento en el que Cristo ya ha salvado a Pedro de hundirse y, de hecho, las aguas se representaron en calma frente a las más embravecidas de la medalla de Nicolás V. Así pues, no cabe interpretar estas diferencias como el resultado de la casualidad o de una decisión arbitraria, sino de una elección consciente que se encuadra con la propia idea que Calixto III tuvo del triunfo de Belgrado: una gracia especial que le concedió la Providencia frente a todos aquellos que no respondieron a su llamada o le acusaron de malgastar el patrimonio de la Iglesia (Schüller 1991: 63).

El encargado de estas acuñaciones también fue Francesco Mariani como confirma su marca personal en las piezas, a pesar de que en el mencionado contrato de arrendamiento no se les dedica ni una sola palabra (Martinori 1918a: 31). En cambio, la responsabilidad en el diseño, al menos en el del cuño del reverso, pudo recaer en Andrea Guazzalotti, una atribución que la historiografía tradicional ha defendido (Martinori 1918a: 31-32) no solo por la relación existente con la escena que representó en la medalla, sino porque también fundió la única coetánea conocida del papa Borgia (CNORP 44). ${ }^{32}$ De cualquier forma, la Navicula Petri tuvo una importante proyección propagandística posterior en el monetario pontificio, bien bajo un tratamiento formal próximo al de Calixto III o representando a San Pedro es su misión de pescador de hombres (V. G. Moneta 2010: 96-97).

\section{Conclusiones}

En general, los poco más de tres años de gobierno de Calixto III como cabeza suprema de la Iglesia católica pueden valorarse en una línea continuista con respecto a la labor política y religiosa de sus más inmediatos predecesores. Para J. F. Mira (2001: 46) las tres preocupaciones más importantes que determinaron las actuaciones del valenciano fueron el reforzamiento de la independencia del poder pontificio, el engrandecimiento de su propio linaje familiar y la puesta en marcha de una cruzada contra el Islam. Y las tres, precisamente, son las que integran los discursos propagandísticos diseñados por la política monetaria pontificia oficial.

En efecto, Martín V (1417-†1431) y Eugenio IV (1431-†1447) se enfrentaron a la dura tarea de reconstruir un Papado debilitado como institución y en su misma autoridad por las negativas

32 La iconografía y epigrafía de esta medalla no permiten relacionarla con un acontecimiento en particular sino, en todo caso, al hecho mismo de su elección como vicario de Cristo en 1455. 
Alberto Aguilera. «Modica fidei quare dubitasti?» Una lectura del pontificado de Calixto III (1455-†1458) a partir de las imágenes monetales

consecuencias de la llamada «cautividad» de Aviñón, el Cisma de Occidente y las tesis conciliaristas. La moneda participó de este proyecto de fortalecimiento y adoptó una línea iconográfica clara, concisa, efectiva y, en el caso de la acuñada en la Urbs, también con fuertes dependencias con la tipología monetal característica aviñonense que ahora, en estos nuevos contextos, podemos decir que se «romanizó», no tanto es su forma como en sus mensajes. Asumida en lo fundamental por Calixto III, contribuyó no solo a configurar y propagar la imagen de la restauración del poder temporal del Papado, sino también la del prestigio espiritual, moral y político perdido. Por esta razón, la tiara como referencia por excelencia de la plena potestad del Papado, la llaves en sotuer como manifestación icónica de la potestas ligandi et solvendi, las mismas figuraciones de San Pedro y San Pablo como columnas de la fe o las de los escudos de armas refuerzan el valor de la primacía petrina y de la sucesión apostólica como garantes de su superioridad por propia decisión divina.

Como hijo de su tiempo, Calixto III no renunció a una afirmación del poder personal como Alonso de Borja y de la glorificación de su linaje y estirpe a través del emblema parlante del toro o buey no «heraldizado», ni tampoco en el proyecto cruzado se apartó de los planteamientos y estrategias diseñadas por Eugenio IV y Nicolás V (Navarro 2002: 21-22). Posiblemente, las principales novedades se encuentran en su iniciativa, en el papel de liderazgo personal que quiso asumir y, en lo que a este trabajo se refiere, en dar visibilidad en la moneda a esas aspiraciones. Bastó con adoptar la conocida alegoría de la Navicula Petri, aparecida en 1455 sobre el reverso de la medalla póstuma de Nicolás V, y redefinirla a unos nuevos tiempos para que irradiara a lo largo y ancho de la Cristiandad la imagen fuerte de la Iglesia y de su Sumo Pontífice que, aunque consciente de los peligros que la amenazaban, de los vientos contrarios que la azotaban, tenía la seguridad de que la barca de la Iglesia era conducida por Cristo y que las puertas del Infierno no prevalecerían contra ella (cfr. Mt. 16, 18).

\section{Bibliografía}

\section{Abreviaturas}

Berman = Berman, A. G. (1991) Papal coins, New York, Attic Books, Ltd.

CNI $=(1910-1943)$ Corpus Nummorum Italicorum, Roma.

CNORP = Modesti, A. (2002) Corpus Numismatum Omnium Romanorum Pontificum, Roma, Accademia Italiana di Studi Numismatici, vol. 1.

Muntoni $=$ Muntoni, F. (1972) Le monete dei Papi e degli Stati Pontifici. Da Adriano I alle Sede Vacante 1559 (772-1559), Roma, P. Santamaria, vol. 1. 
Alberto Aguilera. «Modica fidei quare dubitasti?» Una lectura del pontificado de Calixto III (1455-†1458) a partir de las imágenes monetales

Bibliografía general

Aguilera, A. (2015) Imágenes para una nueva Roma. Iconografía monetal de la Colonia Caesar Augusta en el periodo julio-claudio, Zaragoza, Universidad de Zaragoza.

_. (2016) «Borja y los Borja: la forja de un mito para enaltecer una ciudad», Revista Borja, 5, pp. 1-20.

Ait, I. (2007) «Aspetti dell'attività mercantile-finanziaria della compagnia di Ambrogio Spannocchi a Roma (1445-1478)», Bollettino Senese di Storia Patria, CXIII, pp. 91-129.

- (2011) «Cudi facere in dicta seccha nisi ducatos romanos. Prime considerazioni sulla monetazione a Roma durante i pontificati di Martino V ed Eugenio IV", Annali dell'Istituto italiano di Numismatica, 57, pp. 157-172.

Bascapé, G. C. / Piazzo, M. del. / Borgia, L. (1983) Insegne e simboli: araldica pubblica e privata medievale e moderna, Roma, Ministero per i Beni Culturali e Ambientali / Ufficio Centrale per i Beni Archivistici.

Batllori, M. (dir.) (2002) Diplomatari Borja, 1: Documents de l'Arxiu del Regne de València (1299-1429), València, Edicions Tres i Quatre / IIEB.

Berni, G. (1948) Numismática de los papas españoles, Barcelona, Pedro Bas Vich Impresor.

Bühler, K. (1934/2011) Theory of Language: The representational function of language, Amsterdam / Philadelphia, John Benjamins Publishing.

Bultrini, E. (2013) «Monetazione ed araldica nell'ostentazione dell'aristocrazia romana medievale (secoli XIII-XIV)», RIN, 114, pp. 221-238.

Calbarro, J. L. (2002) «Navis Ecclesiae. Origen e interpretación de una joya iconográfica de Betancuria», Tebeto, 15, pp. 297-309.

Chaves, F. (2009) «Identidad, cultura y territorio en la Andalucía prerromana a través de la Numismática: el caso de Gadir-Gades», Wulff, F. / Álvarez, M. (eds) Identidades, culturas y territorios en la Andalucia prerromana, Málaga / Sevilla, Servicio de Publicaciones de la Universidad de Málaga, pp. 317-359.

- (2012) «Arqueología de la conquista como elemento identitario: moneda y epigrafía monetal», en Santos J. / Cruz, G. Revisiones de Historia Antigua VII. Romanización, fronteras y etnias en la Roma antigua. El caso hispano, Vitoria, Universidad del País Vasco, pp. 173-206.

Company, X. / Garín, F. V. (2006) «La comitencia artística de Alejandro VI en Italia», en Iradiel, P. / Cruselles, J. M. (coord.) De València a Roma a través dels Borja. Congrés conmemoratiu del 500 Aniversari de l'any jubilar d'Alexandre VI, Valencia, Generalitat Valenciana, pp. 329-394.

Crawford, M. H. (1983) «Roman Imperial Coin types and the formation of public opinion», en Brooke, C. N. L. / Stewart, B. H. I. H. / Pollard, J. G. / Volk, T. R. Studies in Numismatic Method Presented to Philip Grierson, Cambridge, Cambridge University Press, pp. 47-64. 
Alberto Aguilera. «Modica fidei quare dubitasti?» Una lectura del pontificado de Calixto III (1455-†1458) a partir de las imágenes monetales

Francisco Olmos, J. M. ${ }^{a}$ (2010): «Alfonso de Borja (1358-1458), papa Calixto III (1455-1458)», en Barrios Pintado, F. (coord.) Francisco de Borja. Santo y duque (1510-2010), Madrid, Fundación Cultural de la Nobleza Española, pp. 188-195.

Francisco Olmos, J. M. ${ }^{a}$ (2012) «La moneda medieval: fuentes documentales para su estudio», en Muñoz Serrulla, M. ${ }^{a}$ T. (coord. y ed.) La Moneda: Investigación numismática y fuentes archivísticas, Madrid, Universidad Complutense de Madrid, pp. 59-96. esta la cambio de sitio.

Friedlaender, J. (1862) Andrea Guazzalotti, scultore pratese: memoria, con un appendice di documenti, Prato, Dalla Tipografia Guasti.

Jakobson, R. y Halle, M. (1967) Fundamentos del lenguaje, Madrid, Ciencia Nueva.

Jones, A.H.M. (1956) «Numismatics and History», en R. A. G. Carson / C. H. V. Sutherland (eds.), Essays in Roman Coinage presented to Harold Mattingly, London, Oxford University Press, pp. 13-33.

López, C. (dir.) (2004) Diplomatari Borja, 2: Documents de l'Arxiu de la Corona d'Aragó (1416-1429), València, Edicions Tres i Quatre / IIEB.

—. (dir.) (2005) Diplomatari Borja, 3: Documents de l'Arxiu de la Corona d'A ragó (1429-1444), València, Edicions Tres i Quatre / IIEB.

(dir.) (2007) Diplomatari Borja, 4: Documents de l'Arxiu de la Corona d'Aragó (1444-1458), València, Edicions Tres i Quatre / IIEB.

Maddalo, S. (2006) «Ritratti, emblemi stemmi: simbologia del potere e immaginario figurativo», en Iradiel, P. / Cruselles, J. M. ' (coord.) De València a Roma a través dels Borja. Congrés conmemoratiu del 500 Aniversari de l'any jubilar d'Alexandre VI, Valencia, Generalitat Valenciana, pp. 395-427.

Martini, R. (1987) «Medaglie di restituzione papali (fine sec. XVI)», Medaglia, 22, pp. 7- 37.

Martinori, E. (1918): Annali della zecca di Roma, Martino V-Eugenio IV, Roma, Istituto Italiano di Numismatica.

_. (1918a): Annali della zecca di Roma, Nicolò V - Callisto III - Pio II, Roma, Istituto Italiano di Numismatica.

Mira, J. F. (2001) Los Borja. Familia y mito, Barcelona, Algar Editorial.

Modesti, A. (1988) «La serie papale di restituzione di Girolamo Paladino», Medaglia, 23, pp. 7-57.

Moneta, V. G. (2010) Santi e monete. Repertorio dei santi raffigurati sulle monete italiane dal VII al XIX secolo, Milano, Università degli Studi di Milano // Facoltà di Lettere e Filosofia.

Montesano, M. (2001) «ll toro dei Borgia: analisi di un simbolo fra tradizione araldica e suggestioni pagane», en M. Chiabò / S. Maddalo / M. Miglio (eds) Roma di fronte all'Europa al tempo di Alessandro VI, Roma, Ministero per i beni e le attività culturali, pp. 759-780.

Mozas, M. de los S. (2003) «El documento numismático como fuente histórica», Códice, 18, pp. 153-160.

SCRIPTA, Revista internacional de literatura i cultura medieval i moderna, núm. 9 / juny 2017 / pp. 232-250

ISSN: 2340 - 4841 doi:10.7203/SCRIPTA.9.10345 
Alberto Aguilera. «Modica fidei quare dubitasti?» Una lectura del pontificado de Calixto III (1455-†1458) a partir de las imágenes monetales

Navarro, M. (2002) «Calixto III, el Papa de la cruzada», Serie histórica, 23, pp. 11-32.

. (2003) Calixto III Borja y Alfonso el Magnánimo frente a la Cruzada, València, Ajuntament de València.

- (2006) Alfonso de Borja, papa Calixto III en la perspectiva de sus relaciones con Alfonso el Magnánimo, València, Institució Alfons el Magnànim / Diputació de València.

—. (2008) Documents per a la història d'Alfons de Borja, papa Calixt III, València, Institució Alfons el Magnànim / Diputació de València.

Paravicini, A. (1994) Il corpo del papa, Torino, G. Einandi.

—. (1998) Le Chiave e la Tiara. Immagini e simboli del papato medievale, Roma, Viella.

(2009) Il potere del papa. Corporeità, autorappresentazione, simboli, Firenze, Sismel Edizioni del Galluzzo.

Prodi, P. (1982) Il sourano pontefice, Bologna, Il Mulino.

Rovelli, A. (2009) «Patrimonium Beati Petri. Emissione e circolazione monetaria nel Lazio settentrionale (XI-XIV secolo)», Annali dell'Istituto italiano di Numismatica, 55, pp. 169-192.

Salcedo, F. (1999) «Imagen y persuasión en la iconografía romana», Iberia 2, pp. 87-109.

Savio, A. y Cavagna, A. (a cura di) (2010) 100 anni del Corpus Nummorum Italicorum, Milano, Società Numismatica Italiana onlus Collana di Numismatica e Scienze affini.

Schüller, S. (1991) Lospapas Borgia. Calixto III y Alejandro VI, Valencia, Edicions Alfons el Magnànim / Institució Valenciana d Estudis i Investigació.

Simonato, L. (2003) «Andrea Guazzalotti», in Dizionario Biografico degli Italiani, Roma, Grosso / Guglielmo da Forlì, Bd. 60, pp. 513-516.

Sutherland, C. H. V. (1983): «The Purpose of Roman Imperial Coin Types», RN, 25, pp. 73-82.

Travaini, L. (2001) «La terza faccia della moneta. Note per lo studio dell `iconografia monetale medievale», Quaderni Medievale, 52, pp. 107-123.

—. (2007) «I ritratti sulle monete. Principi, artisti, collezionismo e zecche nel Rinascimento italiano", in Castagnola, R. (a cura di) Ritratti del Rinascimento, Lugano / Milano, Giampiero Casagrande editore, pp. 83-112.

—. (2007a) «Zecche e monete», in Braustein, Ph. / Molà, L. (a cura di) Il Rinascimento italiano e l'Europa, Treviso, Fondazione Cassamarca / Angelo Colla Editore, vol. 3, pp. 479-509.

- (2007b) Monete e storia nell Italia medievale, Roma, Libreria dello Stato / Istituto poligrafico e Zecca dello Stato.

- (2007c) «La croce sulle monete da Costantino alla fine del medioevo», en Ulianich, B. La croce. Iconografia e interpretazione (secoli I-inizio XVI), Napoli, E. De Rosa, vol. 2, pp. 7-40. 
Alberto Aguilera. «Modica fidei quare dubitasti?» Una lectura del pontificado de Calixto III (1455-†1458) a partir de las imágenes monetales

(2009) «Valori e disvalori simbolici delle monete: temi, problemi, interpretazioni», en L. Travaini ( a cura di) Valori e disvalori simbolici delle monete. I trenta denari di Giuda, Roma, Edizioni Quasar, pp. 13-61.

Velestino, D. (2010) «Imago Gerberti. Un esemplare inedito della collezione numismatica Barberini», en Segismondi, C. (ed.) Orbe novus. Astronomia e Studi Gerbertiani, Roma, Universitalia nella collana Scienza \& Cultura, pp. 124-133.

Villarroel, Ó. (2005) Los Borgia. Iglesia y poder entre los siglos XV y XVI, Madrid, Sílex ediciones.

Zanker, P. (1989) Augusto e il potere delle immagini, trad. it. di Flavio Cuniberto, Torino, Einaudi.

SCRIPTA, Revista internacional de literatura i cultura medieval i moderna, núm. 9 / juny 2017 / pp. 232-250 ISSN: 2340 - 4841 doi:10.7203/SCRIPTA.9.10345 